\title{
Mental health of children with learning disabilities $^{\dagger}$
}

\author{
Pru Allington-Smith
}

\begin{abstract}
Children and adolescents with learning disabilities have high rates of mental health problems and behavioural difficulties. Comorbid disorders such as epilepsy, autism and attention-deficit hyperactivity disorder are common. Despite this, many areas in the UK are failing to provide a psychiatric service for these young people and their families. The children suffer as a result and may have to move away from home unnecessarily, at enormous emotional and financial cost. Each area should have a specialised multidisciplinary health team working closely with colleagues from education and social services to assist these complex children and give them the best chance to fulfil their potential.
\end{abstract}

Life is tough for a child with a learning disability. Negotiating childhood and adolescence and emerging a reasonably balanced adult is hard enough for anyone. We have to grow in our family environment, learn from and survive our schooling, develop enough social skills to make networks outside our families and finally leap into independence having developed a sense of ourselves as unique individuals. What makes this possible is our ability to take in new information and apply it to our lives. The essence of intelligence is the ability to take on difficult situations and think through our options and make the best choices. Is it any wonder that children whose cognitive abilities are limited fail to negotiate these hurdles and often acquire maladaptive patterns of behaviour along the way? Many of the behaviours seen relate to the young person's developmental level, but a person with brain damage for whatever reason is prone to developing emotional and psychiatric problems that may further diminish their capacity to function.

To compound the problem there are often huge hurdles to leap in order to receive help from psychiatric services. In many areas of Britain these services exclude children who have learning disabilities. It is often left to paediatricians to deal with very complex behavioural issues. In regions where there is a service it may be provided by child psychiatrists or by learning disability psychiatrists.

${ }^{+}$For a commentary on this article see pp. $138-140$, this issue.
Current government policy, set out in Standards 8 (Disabled child) and 9 (Child and adolescent mental health) of the National Service Framework for Children, Young People and Maternity Services (the Children's NSF; Department of Health, 2004) stipulates that every local area in England should offer a psychiatric service for children with learning disabilities, but this a recommendation, not a legal requirement. The ongoing failure to provide such services can cause children who might have been supported in their own homes to be placed in distant residential schools or units. Not only is residential care expensive, but placements far from family homes reduce the chances that these children will return to their families and local areas as adults.

\section{Disability or difficulty?}

There are also problems with the terminology used in health and education services to describe the extent of a child's intellectual impairment. The UK health system employs the term 'learning disability', with the subdivisions mild, moderate, severe and profound. This term has little meaning outside of the UK, and indeed in the USA would be used to include specific disorders such as dyslexia. The four subdivisions of learning disability equate to those used in ICD-10 (World Health Organization, 1992) under the international term 'mental retardation'. A child is not said to have a learning disability unless their IQ is below 70 points. The UKeducation system uses the term 'learning difficulty', which it

Pru Allington-Smith is a consultant psychiatrist dually accredited in child and in learning disability psychiatry and employed by North Warwickshire National Health Service Primary Care Trust. She works in a child learning disability team in Coventry and at Brooklands Hospital (Brian Oliver Centre, Brooklands, Coleshill Road, Birmingham B37 7HL, UK. Tel. 0121 329 4930; e-mail: pru.allington-smith@ nhs.net), which has an in-patient service for adolescents who have learning disabilities in addition to severe psychiatric, behavioural or emotional problems. 
usually subdivides into mild, moderate and severe. Achild with a mild learning disability in health terms would probably be described as having a moderate learning difficulty in the education system. Children with mild learning difficulties may have specific educational impairments and will often have IQs higher than 70 .

\section{Recognition and management}

Psychiatrists need to develop the skills to recognise and manage disorders in children with intellectual impairments. This should be done alongside colleagues in a multidisciplinary health team who also have the appropriate skills to work with the young person and their parents or carers. The ultimate aim is to help learning disabled individuals to achieve their full potential in terms of ability and emotional well-being. This will always require multiagency working with education staff and with social services. It must be recognised that dealing with this group is time-consuming and will often need several professionals to work closely together.

Particular expertise is needed in dealing with autism, which is associated with particularly high rates of behavioural and psychiatric problems, especially in children who have moderate or severe learning disabilities. They represent the vast majority of those with severe challenging behaviours.

\section{Prevalence of psychiatric disorder}

A 10-year research project conducted by Michael Rutter and his colleagues included a study of all 10to 12-year-old children living on the Isle of Wight to identify those who had a psychiatric disorder (Rutter et al, 1976). Greatly increased rates were found in children who had learning disabilities, epilepsy or cerebral palsy. Where one or more of these conditions was present the risks were cumulative. Another study, in the London borough of Camberwell (Corbett, 1979), reported an overall rate of $47 \%$ for psychiatric and behavioural disorders in children with a severe or profound learning disability. Similarly high figures were reported by Gillberg et al (1986) in a Swedish urban population.

Although precise figures are hard to come by, the British Paediatric Association (1994) has estimated that an average health district with a population of 250000 would be expected to include 200 children with a severe learning disability. Kiernan \& Qureshi (1993), looking at challenging behaviour, estimated that in such a population there would be about 25 children whose severe learning disability was associated with challenging behaviour that posed a serious management problem. There were also likely
Box 1 Predisposing factors for mental health problems in children with learning disabilities

- Poor communication

- Sensory disability

- Epilepsy

- Physical illness

- Limited range of coping strategies

- Medication

- Abuse

- Behavioural phenotype

to be a significant number of children with mild or moderate learning disabilities who presented with psychiatric or behavioural problems.

Factors predisposing to mental health problems in learning-disabled children are listed in Box 1.

\section{Factors predisposing to behavioural problems}

\section{Communication difficulties}

Many children with learning disabilities have communication problems and some have no speech at all. Additional sensory disabilities, particularly hearing impairment, may further reduce the child's ability to interact with others and to communicate. Consequently, these children may find it hard to understand what is asked of them and even to communicate their basic needs. If you cannot tell your parent that you are wet, cold, thirsty, hungry or in pain, what do you do? You may cry, hit out or hurt yourself. The last two actions work particularly well in attracting the attention of carers, who then have to work out what the problem is.

\section{Poor coping mechanisms}

A lack of coping strategies can lead to reliance on aberrant behaviours when things go wrong. If a child learns that shouting, screaming or becoming aggressive when unable to think of a solution to a problem brings an adult to deal with it or remove them from the situation, such challenging behaviour can become an automatic response to any situation where the child feels uncertain or threatened.

\section{Physical illness and genetic conditions}

Illnesses such as ear infections, dental problems and constipation may not be recognised in children who cannot indicate what is wrong. Children may 
hit the area that hurts, to distract themselves from the pain, or they may respond with an increase in stereotypical behaviours such as rocking. Longstanding physical problems with hips or feet may cause pain, particularly if the child's movements are limited.

Epilepsy is very common in children with learning disabilities and is often complex and difficult to treat. It can be difficult to diagnose seizures in a child who displays stereotypical or bizarre behaviours. A possible tic disorder should also be considered. Frequent seizures are likely to impair concentration and may result in irritability. Anti-epileptics may cause sedation or worsen behaviour.

Some genetic conditions are associated with particular aberrant patterns of behaviour (behavioural phenotypes), and knowing that these are present can lead to better management. A prime example is the prevention of excessive weight gain in individuals with Prader-Willi syndrome, a characteristic of which is an overwhelming urge to overeat.

\section{Environmental factors}

Children with learning disabilities often have low self-esteem. No matter how supportive their families the children know that they cannot do things as well as others. Sometimes they are dysmorphic and often they are poorly coordinated and clumsy. They are frequently mocked by other children and some adults. Society tends at best to pity and patronise them. Depression and anxiety are particularly prevalent in older children as the ability gap between them and their peers continues to widen and becomes more apparent.

Learning-disabled children are more at risk of physical, emotional and sexual abuse than children of normal IQ. It can be hard to form a close bond with a child who is not very responsive and may be physically unattractive. Some parents themselves have learning disabilities and struggle to nurture their children. Sexual predators may target disabled children. Communication difficulties, lack of selfesteem and reliance on adults for personal care increase their vulnerability.

\section{Temper tantrums}

Many young children go through a stage of having temper tantrums when their desires are thwarted. The 'terrible twos' are aptly named. Correct management by parents will help shorten this phase, but in any case children usually grow out of it. This developmental phase may continue for longer in children with learning disabilities and some never successfully negotiate it. Correct management by parents or carers (Allington-Smith, 2006) then becomes essential, but it must be established before the child gets bigger and stronger than the adults.

One of the few things that a child with a learning disability can do as well as their peers is to use their strength. It is not surprising, therefore, that they may use intimidation and aggression to get what they want. A few may come to dominate their households, with disastrous consequences.

\section{Sleep disorders}

Many children with learning disabilities have very poor sleep patterns that typically have been present since infancy. Some seem to have a decreased need for sleep. They may fall asleep quickly but then wake after 3 or 4 hours apparently refreshed, with no daytime drowsiness. Children with autism often find it very hard to settle and it may take them hours once in bed to fall asleep. If sleep can be improved, in both groups there are often improvements in the children's daytime behaviour and concentration levels, with a reduction in irritability.

Sleep deprivation for parents is one of the most important factors leading to family breakdown, be it parental separation or placing the child in social service accommodation.

\section{Establishing a new order}

The first step in the management of poor sleeping patterns is to optimise sleep hygiene. Parents need to establish a regular bedtime routine with a reduction in environmental stimulation. Television and computer games should be removed an hour before sleep time. A hot bath, milky drink and story will often help to settle a child. When the child is in bed, lights should be turned off and the adult should leave the room. The adult may have to stay with the child until they settle but this time should be gradually reduced. When the child wakes during the night the parent should settle them with the minimum of interaction and then withdraw. Initially the child is likely to wake frequently and parents may need to return them to bed many times before they finally sleep.

If these or other measures have been applied consistently but are ineffective, particularly in a child with autism, it may be worth prescribing melatonin in the short term (Dodge \& Wilson, 2001). This hormone is produced by us all in a circadian rhythm and promotes sleep onset. Giving additional melatonin about half an hour before the desired sleep time is often effective in helping the child fall asleep. It is less effective if the sleep problem is early waking, although a slow-release preparation of melatonin 
may be effective for some. Melatonin is currently unlicensed in the UK, but it is widely used off-licence by paediatricians and child psychiatrists. The usual dose range is $1-5 \mathrm{mg}$. Doses above $10 \mathrm{mg}$ seldom give any additional benefit. In many cases the medication can be successfully withdrawn after a month. In a few children it may need to be continued long term. Melatonin may make epilepsy worse, but it can also reduce seizure frequency, particularly if the epilepsy is induced by tiredness. It should also be used with caution in children with a history of asthma.

\section{Attention-deficit hyperactivity disorder}

Attention-deficit hyperactivity disorder (ADHD) is probably more common in children with learning disabilities than in the general population, but is often overlooked. In any assessment the child's developmental level needs to be borne in mind, particularly when considering whether attention problems are present. Although the rating scales that are available, for example Conner's questionnaires (Conners et al, 1998), are standardised on normal populations they can nevertheless be useful. They must be used alongside a detailed clinical history, particularly in deciding whether the child's problem occurs outside of the home. They can also be used to assess a response if medication is used. Unfortunately the presence of a learning disability is an exclusion criterion for some of the assessment tools used in the UK to diagnose ADHD. This has meant that young people have been denied treatment that can significantly help them to achieve their full potential.

Stimulant medication is still the mainstay of treatment (MTA Cooperative Group, 1999), but learning-disabled children seem to be more prone to side-effects, particularly appetite suppression, and weight needs to be closely monitored. If weight loss is a problem or stimulants are not tolerated, I have found atomoxetine in standard doses to be a useful alternative.

\section{Depression}

Depression in children with learning disabilities can be hard to detect. Such children are less likely to express hopelessness and low mood and may have times when they appear to be happy. Appetite is usually affected but may increase or decrease. There may be early morning wakening or excessive sleep. Poor concentration and anhedonia are common. The child may appear to lose skills. An increase in stereotypical behaviour such as rocking may occur.
It is important to obtain a baseline measurement of the child's previous level of functioning.

In the UK, the National Institute for Health and Clinical Excellence (NICE) has now issued guidance on the treatment of childhood depression (National Collaborating Centre for Mental Health, 2005). This recommends that cognitive-behavioural therapy (CBT) be used in preference to medication. If medication is required for severe depression or when psychotherapeutic interventions have not been beneficial or have been refused, it advocates fluoxetine as first-line treatment, with sertraline and citalopram as the only second-line agents. However, the document makes it clear that children with learning disabilities were not considered specifically or separately in drawing up the guidelines.

It may be possible to adapt CBT for more-able children, but antidepressant medication still has a place, particularly for less-able children who are unlikely to benefit from CBT. Children with autism may find it impossible to apply CBT techniques learnt in a clinic setting to everyday life.

\section{Self-talk and psychosis}

True psychotic illnesses are fortunately uncommon, but learning-disabled children are often referred because they talk to themselves. Self-talk is a developmental phenomenon and should not be confused with psychosis. The history is often that the child is heard talking to themselves in their room. Both sides of the conversation can be heard and the child often shouts or sounds upset. The child is otherwise behaving in their normal fashion. On careful analysis the child may be repeating conversations that have taken place in the recent past. This time round the child may change the outcome of an argument or give voice to emotions that they were unable to express at the time. Self-talk seems to me to be particularly common in children with Down's syndrome.

The emergence of schizophrenia in childhood in someone with a learning disability is nearly always associated with a change in personality and a reduction in functional abilities. The child is less likely to have complex delusional ideas and more likely to experience visual or tactile hallucinations. The prognosis for early-onset schizophrenia is generally poor. The presence of affective symptoms should raise the question of a bipolar disorder.

If psychosis is suspected, it is essential to perform brain imaging (computed tomography or magnetic resonance imaging) and an electroencephalogram that includes frontal leads. Frontal and temporal lobe epilepsy can be associated with psychosis, although the epilepsy usually precedes the psychosis by a 
number of years. The presence of genetic conditions associated with psychosis, particularly velo-cardiofacial syndrome and Prader-Willi syndrome, should also be investigated.

\section{Autistic-spectrum disorders}

Thenumber of children with pervasive developmental disorders such as autism is difficult to assess because of the differing classifications. In an informative review of epidemiological studies, Fombonne (2003) gives a conservative estimate of the prevalence of all pervasive developmental disorders of at least $27.5 / 10000$, but reports that the figure may be nearer twice that if only the more recent surveys are included.

Autism, in its narrowest definition, is associated with a learning disability in $70 \%$ of cases. When the wider category of pervasive developmental disorder is used (this includes sub-categories such as Asperger syndrome and pervasive developmental disorder not otherwise specified), the association with a learning disability falls to $24 \%$. De Bildt et al (2003), in their review of prevalence studies, estimated the rate of pervasive developmental disorder to be between 7.8 and $19.8 \%$ in children and adolescents with learning disabilities. Young people with autistic-spectrum disorders are over-represented among those who have problem behaviours.

\section{Understanding autism}

Professionals seeing children with autism need a thorough understanding of the disorder. Educating parents about autistic disorders (Boxes 2-4) gives them a better insight into the way that their child perceives the world. This in turn leads to more effective behavioural management at home as well as increased empathy with the child. Parents may have been told that their child is just naughty or that they are failing as caregivers. The child's behaviour is usually bizarre and sometimes frightening. At

Box 2 Behavioural problems in autism

- Restrictive diet

- Sleep problems

- Insistence on sameness

- Obsessive interests

- Aggression

- Extreme anxiety

- Self-injury

- Tantrums

- Socially inappropriate behaviours
Box 3 Triggers for behavioural problems in autism

- Changing activities

- Noise

- New situations

- Unfamiliar people

- Routines not adhered to

- Environmental changes

the time of referral, parents are often demoralised, with feelings of guilt or blame. Finally to be given an explanation of why their child behaves as he or she does nearly always comes as an enormous relief. Families can be given contact details for autism support organisations, most of which are excellent. The National Autistic Society has a particularly helpful website and online bookshop (http://www.nas.org.uk) and telephone helpline (0845 0704004$)$.

\section{Management of autism}

Problem behaviours of children with autisticspectrum disorders (Boxes 2 and 3) are often situational as the children may conduct themselves very differently in various environments. They usually behave worst at home. A child who has mastered the task of feeding herself at school may refuse to do so at home, her safe haven where she might have more control over keeping everything unchanged. More-able children with autistic-spectrum disorders can be desperate to conform to the rules at school at the expense of mounting anxiety that can erupt the moment they step through their front door. Parents may not be believed about the severity of problem behaviour at home because the school has never seen it.

Box 4 describes how it can feel to have autism. Most of the behavioural problems mentioned are mediated through anxiety, and most of the management strategies described below are aimed at reducing the child's high anxiety level.

\section{Establishing communication}

Most children with autism find it easier to understand visual rather than verbal information, even when their use of language is good. Providing a visual sequence of forthcoming events can help them understand what is expected of them and, crucially, when they will return to a place or an activity that makes them feel safe. The sequence may be very short, showing just the next activity, or it may encompass the entire day. The sequence might use objects of reference (e.g. a seat belt strap to indicate 


\section{Box 4 How it feels to have autism}

If you have an autistic-spectrum disorder the world you inhabit is a very scary place. If you cannot predict what other people may be thinking or feeling, any change in your normal routine can throw you into a panic. A new school escort, school bus, or teacher can precipitate an outburst of extreme agitation. Problems filtering out sensory information can make some places intolerable. In a supermarket it may be the hum from the overhead strip lights, the fans in the fridges, the echoing of voices, the hordes of strange unreadable people or the fact that you cannot predict how long you will have to endure the outing before you are returned to the safety of your home.

A screaming fit or aggression will usually lead to you being removed to a place you feel safe. To prevent such experiences you may refuse to leave the house, strip off your clothes or work yourself up into such a state that you vomit.

a car ride), photographs, symbols or written words, depending on the child's level of understanding. Assessment by a speech and language therapist will indicate the best modality to use.

Most special schools for children with severe learning disabilities use a 'total communication environment', where signing and symbols are used as a matter of course alongside speech. The Picture Exchange Communication System (PECS) (Bondy \& Frost, 1994) has been particularly beneficial. A key role of speech and language therapists in such schools is to train the school staff to use PECS with all the children. They should also encourage and teach parents to use PECS with their child at home.

\section{Improving the environment}

Simple adaptations to the children's physical environment can help them. In schools or residential care in particular, rooms can be made less 'busy' by siting screens so that a child is not distracted or upset by people walking past and by allowing the child to face a blank wall to help them focus on a task. It is helpful to have a quiet room where a child can calm down when agitated. In the home, a room where the child can calm down or be safe when the parent has to be elsewhere is invaluable.

\section{Sensory and music therapy}

Sensory integration work can be extremely helpful for children who react badly to environmental stimuli, perhaps finding touch and certain textures hard to tolerate (Bogdashina, 1996). It enables people to work more directly with a child in reciprocal interactions. A specialised occupational therapist can advise on aids for individual children: weighted jackets, for example, help some to reduce their anxiety. Music therapy by a trained music therapist is thought by many to help children understand the function of reciprocal communication and to learn how to begin to respond to other people (Eschen, 2002).

\section{Diet}

Restricted diet can be a real difficulty, particularly in younger children. A child may only eat a limited number of foods and even those may have to be particular brands. In extreme cases this can lead to severe malnutrition and growth retardation. The combined forces of a dietitian and speech and language therapist are often required.

Parents themselves often impose a particular diet in an attempt to improve the behavioural problems of children with autistic-spectrum disorders. Exclusion diets (particularly gluten and casein) and supplements such as fish oils and vitamin B6 are common. The possible benefits of these dietary manipulations have yet to be rigorously evaluated.

\section{Adolescence}

For most young people adolescence is a time of growing independence and the development of a sense of identity. They learn by taking risks and by taking and evaluating other people's ideas. They leave school, find a job and develop sexual relationships. For a young person with a learning disability adolescence happens late and is often prolonged. Few achieve independence and leaving school can result in a loss of opportunities to do things for themselves. Sexual feelings emerge but appropriate relationships are hard to achieve and often blocked by well-meaning carers. This can lead to enormous frustration for the individual and the emergence of power struggles in the household. The young adult may seek an area of control and use their physical strength to get it. Parents of children with autisticspectrum disorders often find it hard to let them move on, constantly trying to protect them from the harsh realities of daily life. Adolesence is also the peak risk time for serious mental illnesses to emerge, particularly depression.

\section{Young offenders}

Young offenders with learning disabilities who have been convicted generally have mild impairment and have been felt to have the capacity to understand that their offending behaviour was unlawful. Those 
Box 5 Essential components of a children's community learning disability team

- One or more psychiatrists

- Community nurses trained in learning disability (registered nurses in learning disability) and/or mental health (registered nurses in mental health)

- Clinical psychologists

- Behavioural specialists, who may have clinical psychology, nursing or even social work backgrounds

- Speech and language therapists

- Occupational therapists trained in sensory integration

- Community dietitian

who have more severe learning disabilities lack the capacity to be aware of the real nature of their offences and are usually not prosecuted. Young people with learning disabilities are sometimes led by other children into petty crime during which they are often caught because of their lack of sophistication. Arson and sexual offences are the most frequent of the serious crimes.

Treatment programmes have been developed for learning-disabled adult offenders (Lindsay, 2002) and the principles they utilise could be employed with children. For arsonists, the main aim is for the offender to realise the potential risk to others of what they are doing. Sexual offenders have often been abused themselves or are seeking out sexual partners of a similar developmental level to themselves. Their treatment usually involves sex education and work on denial, motivation, relapse prevention and past abuse that they have suffered.

\section{Service provision}

As already mentioned, the establishment of comprehensive services for children and adolescents with learning disabilities is now a clear priority set out in the Children's National Service Framework (Department of Health, 2004). New developments will probably come out of child and adolescent mental health services (CAMHS), but existing provision is as likely to be based in learning disability psychiatric services. The essential components of such a team are listed in Box 5. With the most challenging of children team members will need to work closely together. Excellent working relationships with social work colleagues, teachers and education departments are also essential. A child with severe behavioural problems is likely to be causing problems not only at home, but also in school, in residential respite services and in the community. Professionals need to be prepared to work in all of these settings.

Guidance on the provision of services for children with learning disabilities has been produced by the Royal College of Psychiatrists (2004).

In-patient services are currently a scarce resource and as a result many learning-disabled children are inappropriately placed with private organisations or in secure social services accommodation. Ideally, each region should have an in-patient unit. The lack of in-patient facilities in London and the south-east of England is of major concern. Units intended for children with learning disabilities should be sited within either CAMHS in-patient provision or a learning-disability hospital. Most children who require admission have significant problems managing aggression and staff require training in appropriate restraint techniques and a high level of external supervision and support from senior nursing staff. The children have often had large gaps in their schooling, so educational provision in these units is vital.

\section{Medication for behavioural problems}

The use of medication for the behavioural problems of children with learning disabilities is a contentious issue. It should be used sparingly and only when other management strategies have been tried and failed. It should never be used because other more appropriate treatment methods are not readily available. Most of the medications currently prescribed are not licensed for children or for the management of behavioural problems. Drug trials have not included children with learning disabilities and there is little, if any, information on the risk of adverse effects, particularly during long-term treatment. When medication is used the patient should be closely monitored by the prescribing physician, who must record a clear diagnosis and a rationale for medication use.

The most common scenario is that of a child (usually a boy) with autism whose raised anxiety levels are resulting in severe aggression or selfinjury and who has not responded to behavioural management, speech and language support and consideration of sensory and environmental requirements. The family may not be able to continue to care for him or he may pose a significant threat of harm to others, most often to the mother and siblings. The aim of medication would be to reduce the child's anxiety levels so that he is less likely to become agitated to the point of violence, thus allowing other management strategies to proceed. 


\section{Carbamazepine}

Carbamazepine can be effective in learning-disabled children with poor impulse control that leads to significant aggression. Dosage depends on the size and age of the child but is generally less than that used in the treatment of epilepsy (maximum of $600 \mathrm{mg}$ daily in divided doses). Such children should also be evaluated for the presence of symptoms of ADHD and treated accordingly (see above).

\section{Selective serotonin reuptake inhibitors}

In more-able older children with autism the anxiolytic properties of a selective serotonin reuptake inhibitor such as fluoxetine may be helpful, particularly if there is also evidence of low mood. The dose should be started low, i.e. $5 \mathrm{mg}$, and increased to a maximum of $20 \mathrm{mg}$, depending on the age of the child.

\section{Risperidone}

The antipsychotic risperidone also has good anxiolytic properties when used at a much lower dose than would be used to treat psychosis. Irrespective of their age or size, I always start children on $0.25 \mathrm{mg}$ and allow a month to assess the response fully. Doses above $1 \mathrm{mg}$ per day are seldom indicated. Risperidone is at present unlicensed for children or for use in autism. It often produces an increase in appetite and weight gain, so children should be weighed regularly. Many children also become constipated after a time, but this usually responds to osmotic laxatives. Risperidone can also cause stomach ache and headaches. Extrapyramidal side-effects can occur even at lower doses and there is a risk of tardive dyskinesia. Raised prolactin levels can cause gynaecomastia and even, rarely, galactorrhoea. There is currently a debate about whether regular blood tests should be employed in children treated with risperidone.

\section{Conclusions}

The recommendations of the Children's NSF have given a clear message that psychiatric services must specifically consider and cater for children who have learning disabilities and behavioural, emotional or psychiatric problems. Not to do so risks family breakdown, with children being placed unnecessarily away from home. This also has major financial implications for health, education and social services. Services need to work closely together around the often complex needs of the child and the family.

\section{References}

Allington-Smith, P. (2006) Psychiatric and behavioural disorders in children and adults with intellectual disabilities. In The Psychiatry of Intellectual Disability (eds A. Roy, M. Roy \& D. Clarke), pp. 95-105. Oxford: Radcliffe.

Allington-Smith, P., Ball, R. \& Haytor, R. (2002) Management of sexually abused children with learning disabilities. Advances in Psychiatric Treatment, 8, 66-72.

Bogdashina, O. (1996) Sensory Perceptual Issues in Autism and Asperger Syndrome: Different Sensory Experiences - Different Perceptual Worlds. London: Jessica Kingsley.

Bondy, A., \& Frost, L. (1994). The picture exchange communication system. Focus on Autistic Behavior, 9, 1-19.

British Paediatric Association (1994) Services for Children and Adolescents with Learning Disability (Mental Handicap). Report of a British Paediatric Association Working Party. London: British Paediatric Association (now the Royal College of Paediatrics and Child Health).

Conners, C. K., Parker, J. D. A., Sitarenios, G., et al (1998) The Revised Conners' Parent Rating Scale (CPRS-R). Factor structure, reliability, and criterion validity. Journal of Abnormal Child Psychology, 26, 257-268.

Corbett, J. (1979) Psychiatric morbidity and mental retardation. In Psychiatric Illness and Mental Handicap (eds F. E. James \& R. P. Snaith), pp. 11-25. London: Gaskell.

de Bildt, A., Systema, S., Ketelaars, C., et al (2003) Measuring pervasive developmental disorders in children and adolescents with mental retardation: a comparison of two screening instruments used in a study of the total mentally retarded population from a designated area. Journal of Autism and Developmental Disorders, 33, 595-605.

Department of Health (2004) National Service Framework for Children, Young People and Maternity Services. London: Department of Health.

Dodge, N. N. \& Wilson, G. A. (2001) Melatonin for treatment of sleep disorders in children with developmental disabilities. Journal of Child Neurology, 16, 581-584.

Eschen, J. T. (ed.) (2002) Analytical Music Therapy. London: Jessica Kingsley.

Fombonne, E. (2003) Epidemiological surveys of autism and other pervasive developmental disorders: an update. Journal of Autism and Developmental Disorders, 33, 365-382.

Gillberg, C., Persson, E., Grufman, M., et al (1986) Psychiatric disorders in mildly and severely mentally retarded urban children and adolescents: epidemiological aspects. British Journal of Psychiatry, 149, 68-74.

Kiernan, C. \& Qureshi, H. (1993) Challenging behaviour. In Research to Practice? Implications of Research on the Challenging Behaviour of People with Learning Disabilities (ed. C. Kiernan), pp. 53-85. Kidderminster: British Institute of Learning Disabilities.

Lindsay, W. R. (2002) Research and literature on sex offenders with intellectual and developmental disabilities. Journal of Intellectual Disability Research, 46 (suppl. 1), 74-85.

MTA Cooperative Group (1999) A 14 month randomised controlled trial of treatment strategies for attention deficit/ hyperactivity disorder. Archives of General Psychiatry, 56, 1073-1086.

National Collaborating Centre for Mental Health (2005) Depression in Children and Young People. Identification and Management in Primary, Community and Secondary Care. National Clinical Practice Guideline No. 28. London: British Psychological Society. http://www.nice.org.uk/pdf/ cg028fullguideline.pdf

Royal College of Psychiatrists (2004) Psychiatric Services for Children and Adolescents with Learning Disabilities (Council Report CR123) London: Royal College of Psychiatrists. http:// www.rcpsych.ac.uk/publications/cr/cr123.htm

Rutter, M., Tizard, J., Yule, W., et al (1976) Isle of Wight Studies, 1964-74 Research Report. Psychological Medicine, 6, 313-332.

World Health Organization (1992) The ICD-10 Classification of Mental and Behavioural Disorders. Geneva: WHO. 


\section{MCQs}

1 An increase in behavioural problems in a child with a learning disability can be a consequence of:

a constipation

b poor seizure control

c communication problems

d anti-epileptic medication

e physical abuse.

2 In children with learning disabilities, attentiondeficit hyperactivity disorder:

a cannot be diagnosed

$\mathrm{b}$ requires different medication from that used for other children

c should be diagnosed in the context of the child's developmental level

d medication is more likely have side-effects

e is often diagnosed.

3 Psychosis in children with learning disabilities:

a is a common diagnosis

b often presents as 'self-talk'

c can be associated with a genetic disorder

d responds to antipsychotic medication

e is usually associated with a change in personality.
4 Behavioural problems in children with autism and learning disabilities:

a are common

b can be provoked by minor changes in routine

c are seldom associated with high anxiety levels

$\mathrm{d}$ may be helped by the use of a visual timetable

e are likely to be the same in all environments.

5 Medication for behavioural problems in learning disability:

a is widely accepted

b has been well studied

c should be used only under specialist supervision

d may be used to reduce anxiety in autism

e can be used without a clear diagnosis.

\section{MCQ answers}

\begin{tabular}{|c|c|c|c|c|}
\hline 1 & 2 & 3 & 4 & 5 \\
\hline a $\mathrm{T}$ & a $\mathrm{F}$ & a F & a $\mathrm{T}$ & a $\mathrm{F}$ \\
\hline b $\mathrm{T}$ & b F & $b F$ & b $\mathrm{T}$ & b F \\
\hline c $\mathrm{T}$ & c $\mathrm{T}$ & c $\mathrm{T}$ & c F & c $\mathrm{T}$ \\
\hline $\mathrm{d} T$ & $\mathrm{~d} \mathrm{~T}$ & $\mathrm{~d} T$ & $\mathrm{~d} \mathrm{~T}$ & $\mathrm{~d} \mathrm{~T}$ \\
\hline e $\mathrm{T}$ & e $F$ & e $\mathrm{T}$ & e $F$ & e $F$ \\
\hline
\end{tabular}

\section{The new developmental psychiatry}

INVITED COMMENTARY ON...

MENTAL HEALTH OF CHILDREN WITH LEARNING DISABILITIES

Tom Berney

Abstract Psychiatric services for children and adolescents with learning disabilities have been subject to fashion and aspiration rather than pragmatic planning, at different times being claimed by different specialties. As services have atrophied, it has become clear how distinct are the clinical issues that arise in this group; issues that show developmental psychiatry at its starkest with a combination of organic, dynamic and systemic factors that require community teamwork. As services and specialties regroup, this evolving area is likely to continue defining itself, perhaps taking in adults with developmental disorders, to emerge as a new specialty, developmental psychiatry. It remains to be seen where this will sit within the health service.

Thirty years ago, 'mental handicap' psychiatrists routinely worked across the whole lifespan but much of their time was taken up with patients under
18 years old. Times changed; children were educated in special schools rather than being trained in social service centres and child psychiatry declared its

Tom Berney is a consultant in developmental psychiatry with Northgate and Prudhoe NHS Trust (Prudhoe Hospital, Prudhoe, Northumberland NE42 5NT, UK. E-mail: t.p.berney@ncl.ac.uk). 